\title{
Enlargement of Extraspinal Cysts in Spinal Dysraphism : A Reason for Early Untethering
}

\author{
Kyung Hyun Kim, ${ }^{1}$ Kyu-Chang Wang, ${ }^{1}$ Ji Yeoun Lee ${ }^{1,2}$ \\ Division of Pediatric Neurosurgery, Seoul National University Children's Hospital, Seoul, Korea \\ Department of Anatomy and Cell Biology, ${ }^{2}$ Seoul National University College of Medicine, Seoul, Korea
}

Some types of spinal dysraphism can be accompanied by extraspinal cysts, including myelomeningocele, myelocystocele, myelocele, meningocele, limited dorsal myeloschisis, lipomyelomeningocele, and terminal myelocystocele. Each disease is classified according to the developmental mechanism, embryologic process, site of occurrence, or internal structure of the extraspinal cyst. In most cystic spinal dysraphisms except meningocele, part of the spinal cord is attached to the cyst dome. Most open spinal dysraphisms pose a risk of infection and require urgent surgical intervention, but when the cyst is accompanied by closed spinal dysraphism, the timing of surgery may vary. However, if the extraspinal cyst grows, it aggravates tethering by pulling the tip of the cord, which is attached to the dome of the cyst. This causes neurological deficits, so urgent surgery is required to release the tethered cord.

Key Words : Extraspinal cyst · Spinal dysraphism · Untethering · Intraoperative neurophysiologic monitoring · Tethered cord.

\section{INTRODUCTION}

There are several representative entities among spinal dysraphisms that exhibit extraspinal cysts, such as myelomeningocele, myelocystocele (MMC), meningocele, limited dorsal myeloschisis (LDM), lipomyelomeningocele (LMMC) and terminal myelocystocele (TMCC). Since extraspinal cysts are filled with cerebrospinal fluid (CSF), it can be assumed that there is room for enlargement by CSF hydrodynamics (pulsating motion and pressure of the CSF), but the mechanism of cyst enlargement is not exactly known. In fact, some spinal dysraphisms with enlarging cysts require special attention to the progression of neurological deficits. In addition, there is not much reference about the definition of these spinal dysraphisms with cysts or explanations for the enlargement in the cyst size. Through this article, we describe details on each condition of spinal dysraphism and postulate the pathomechanisms resulting in increasing cyst size and neurological deficits. We would like to suggest an adequate timing of the surgery in normal skin covered closed spinal dysraphism with an extraspinal cyst.

- Received : March 27, 2020 •Revised : April 1, 2020 •Accepted : April 9, 2020

- Address for reprints : Ji Yeoun Lee

Department of Anatomy and Cell Biology, Seoul National University College of Medicine; Division of Pediatric Neurosurgery, Seoul National University Children's Hospital, 101 Daehak-ro, Jongno-gu, Seoul 03080, Korea

Tel : +82-2-740-8205, Fax : +82-2-749-3485, E-mail : femiddang@naver.com, ORCID : https://orcid.org/0000-0003-0464-7605

This is an Open Access article distributed under the terms of the Creative Commons Attribution Non-Commercial License (http://creativecommons.org/licenses/by-nc/4.0) which permits unrestricted non-commercial use, distribution, and reproduction in any medium, provided the original work is properly cited. 


\section{TYPES OF SPINAL DYSRAPHISM WITH EXTRA- SPINAL CYSTS}

MMC is the most common open neural tube defect and is characterized by extruded neural placode on the skin surface.

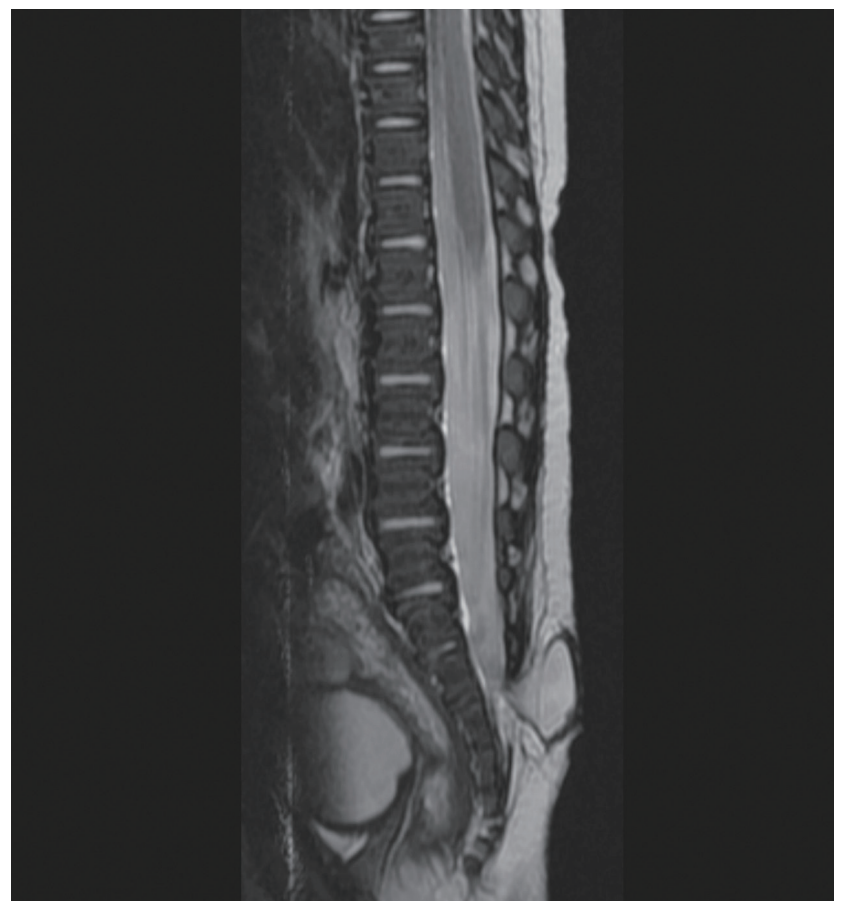

Fig. 1. Meningocele without any neural structure inside the sac.

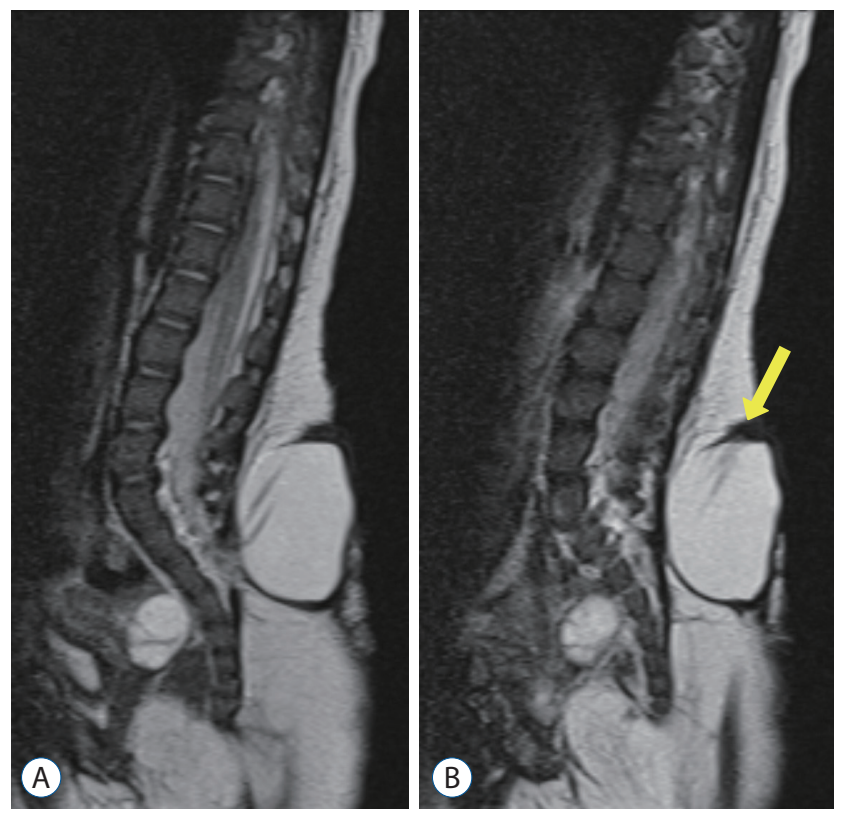

Fig. 2. A : Saccular type of limited dorsal myeloschisis. B : Note the stalk to dome (yellow arrow).
A CSF-filled sac containing the spinal cord and usually some nerve roots is frequently seen. Meningocele also has a CSFfilled meningeal cyst protruding through the spinal laminar defect. However, meningocele is characterized by no skin defects, and no neural structures are found in the cyst (Fig. 1).

Extraspinal cysts may also be found in LDM. LDM is defined as a focal "closed" midline skin defect and fibroneural stalk that is attached to the skin lesion from the cord. Accord-
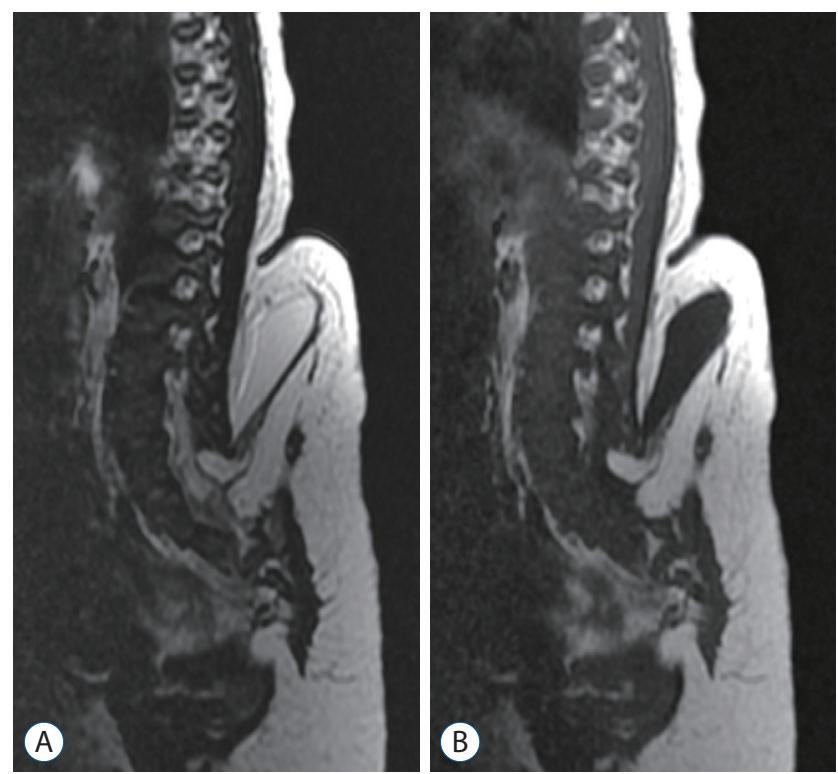

Fig. 3. 'True' lipomyelomeningocele shows the herniated spinal cord with fat tissue and cerebrospinal fluid in the dural sac through the fascial defect. A : T2-weighted imaging. B : T1-weighted imaging.

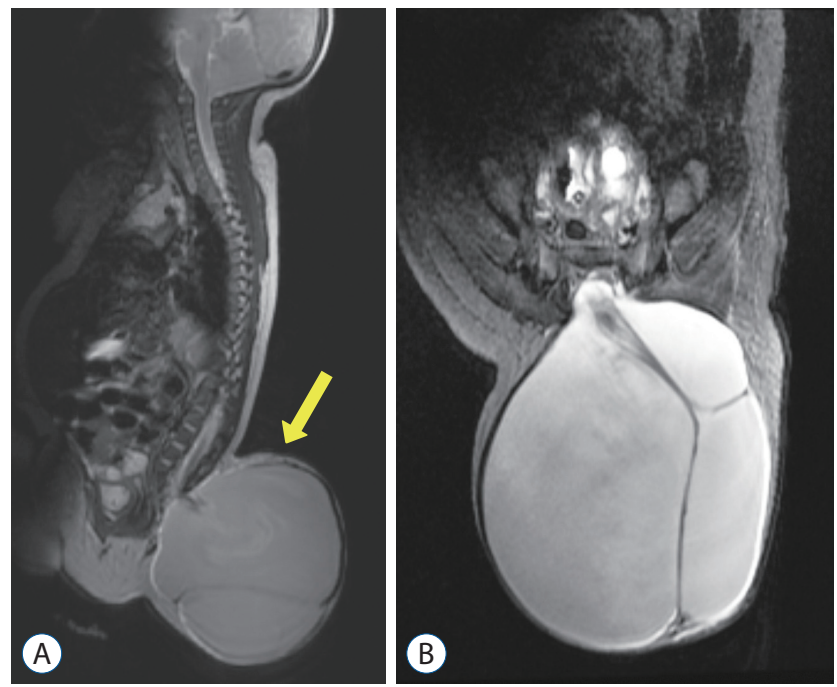

Fig. 4. Terminal myelocystocele. Note the low-lying syringomyelic spinal cord (yellow arrow). A : Sagittal section. B : Axial section. 
ing to the classification of Pang, there are saccular types (stalk to dome, basal neural nodule, and segmental myelocystocele) in LDM that can be accompanied by an extraspinal cyst (Fig. 2). Seemingly the same extraspinal cyst, but in fact, the layers that make up the cyst are different in the myelocystocele versus the nonmyelocystocele form of a saccular LDM. In the former category, the fluid is commonly in a hydromyelic cavity with ependymal lining; in the latter category, the cyst is composed of CSF in the subarachnoid space.

LMMC will also likely have an extraspinal cyst, as a dural sac containing neural tissue which may be attached to the subcutaneous lipoma. However, as LMMC is sometimes used as a term to refer to lumbosacral lipoma in general, it should be clarified that the extraspinal cyst may be found only in a ‘true' LMMC (Fig. 3).

TMCC $^{4,8)}$ is a skin-covered lumbosacral spinal dysraphism with an arachnoid-lined meningocele directly connected to the spinal subarachnoid space and a low-lying syringomyelic spinal cord. Ependymal and dysplastic glial cells line the terminal cyst, which is directly continuous with the dilated central canal of the cord (Fig. 4) ${ }^{5}$. Magnetic resonance image shows a 'trumpet-like' flaring of the distal cord central canal into an ependymal-lined terminal cyst.

\section{CLINICAL IMPLICATIONS OF EXTRASPINAL CYST ENLARGEMENT}

In the literature, there are cases in which symptoms have newly or rapidly developed with cyst enlargement in LMMC and TMCC. Lee et al. ${ }^{4)}$ reported cases of cyst enlargement in TMCC and symptomatic progression with cyst enlargement. According to their case report, there were four patients with cyst enlargement out of eight TMCC patients who underwent surgery. The four patients showed concurrent progression of neurological symptoms, motor weakness or neurogenic bladder. One patient was fortunate to be detected early and had a dramatic improvement in postoperative muscle strength, but the others had persistent neurological symptoms after surgery, although neurological deterioration did not worsen. Rapid deterioration was not seen in the four patients without cyst enlargement during the preoperative period.

It seems that cyst enlargement may cause cord tethering by traction (pulling) of the spinal cord. However, some researchers have disregarded the correlation of cyst enlargement with the progression of neurological deficits. The reports usually contained limited assessments of urinary dysfunction ${ }^{1,3,6)}$. Although the mechanisms underlying cyst enlargement are not clear, young children (under 6 weeks) are much more prone to cyst enlargement than patients of older ages ${ }^{7}$. It should be noted that as the cyst in meningocele does not contain neural tissue, enlargement in such cases does not cause neurological deterioration.

\section{PATHOMECHANISMS OF THE PROGRESSIVE NEUROLOGICAL DEFICITS BY CYST ENLARGE- MENT}

Kim et al. ${ }^{2)}$ reported a case that showed that cyst enlarge-
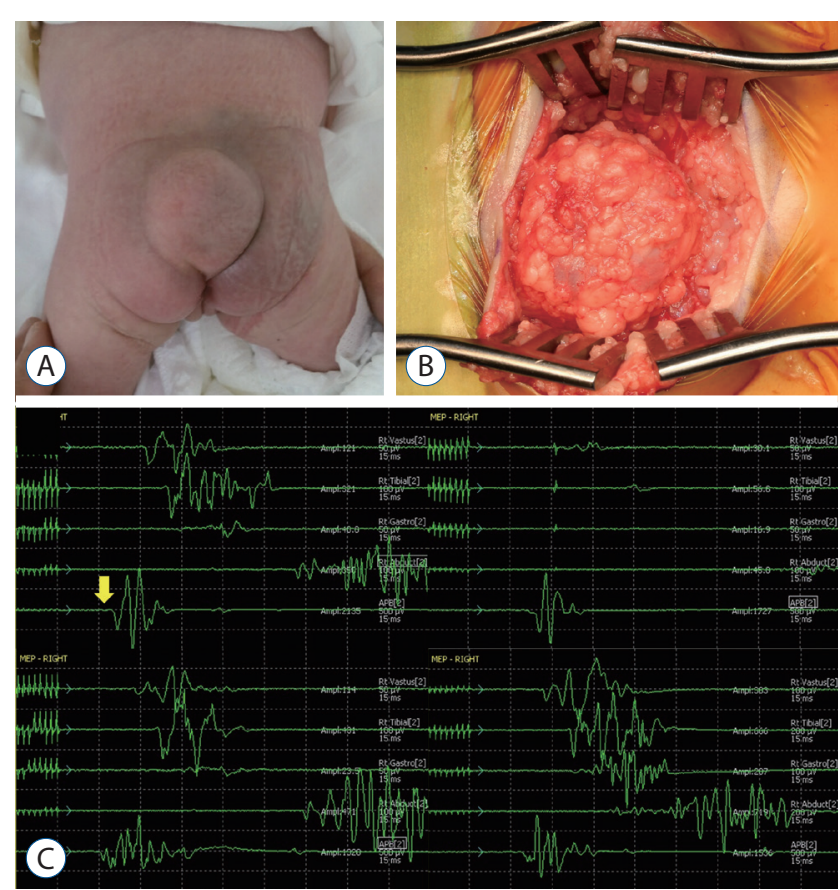

Fig. 5. A : A gross photo of the patient shows a cystic mass in the back. $B:$ An operative photo shows the cystic mass herniated through the fascial defect (right - cephalad side of the patient). C : Tracings of motor evoked potentials (MEPs) demonstrate changes in MEPs during the operation. The baseline MEPs were recorded at the start of surgery (left upper). Decreases in MEPs in both lower extremities were noticed. Only the right-side tracings are shown in this figure (from top to bottom : vastus medialis, anterior tibialis, gastrocnemius, abductor hallucis, adductor pollicis brevis). Please note that there was no change in the control MEPs in the upper extremity from abductor pollicis brevis (yellow arrow) (right upper). After aspiration of cerebrospinal fluid, the signal appeared again immediately (left lower) and was fully recovered after 20 minutes (right lower). Adopted from Kim et al. ${ }^{2)}$, with permission from Springer Nature. 
ment can induce neurological deficits. The patient had LMMC, and during the early stage of untethering surgery, the cyst was peeled off the overlying skin and dissected from the muscle fascia. As the cyst was freed from the surrounding tissue, which was confining and compressing the cyst sac, the cyst started to slightly increase in size as more CSF was drained into the 'freed' cyst (Fig. 5). Then, the evoked potential on the intraoperative neurophysiologic monitoring (IONM) started to decrease and disappeared. When aspiration of the cyst was attempted, the IONM signal was recovered in real time (Fig. 5C).

The two abovementioned studies by Lee et al. ${ }^{4)}$ and Kim et al. ${ }^{2)}$ explain that when the cord is tethered to the cyst wall, the cyst becomes larger and pulls the cord, which results in rapid development of neurological symptoms. Both papers emphasized that in the presence of cyst enlargement, urgent decompression was able to improve the patient's neurological prognosis.

\section{CONCLUSION}

Enlargement of an extraspinal cyst in spinal dysraphism can cause rapid progression of neurologic symptoms, including bladder dysfunction, by pulling the neural structures attached to the cyst wall. Hence, rapid enlargement of the cyst may require urgent surgery.

\section{CONFLICTS OF INTEREST}

No potential conflict of interest relevant to this article was reported.

\section{INFORMED CONSENT}

This type of study does not require informed consent.

\section{AUTHOR CONTRIBUTIONS}

Conceptualization : KHK, KCW, JYL

Data curation : KHK

Formal analysis : KHK
Funding acquisition : JYL, KCW

Methodology : KHK

Project administration : JYL

Visualization : KHK, KCW, JYL

Writing - original draft : KHK

Writing - review \& editing : KCW, JYL

\section{ORCID}

Kyung Hyun Kim https://orcid.org/0000-0002-8238-2043

Kyu-Chang Wang https://orcid.org/0000-0001-7440-6650

Ji Yeoun Lee https://orcid.org/0000-0003-0464-7605

\section{- Acknowledgements}

This research was supported by the Bio \& Medical Technology Development Program of the National Research Foundation (NRF) of Korea funded by the Ministry of Science \& ICT (NRF-2018-M3A9H3021707).

\section{References}

1. Gupta DK, Mahapatra AK : Terminal myelocystoceles: a series of 17 cases. J Neurosurg 103(4 Suppl) : 344-352, 2005

2. Kim KH, Chong S, Lee JY, Kim K, Kim SK, Wang KC : Decreased MEPs during subcutaneous dissection for untethering surgery of a "true" lipomyelomeningocele: aggravated traction of the spinal cord by release of the sac from the original nest. Childs Nerv Syst 35 : 529-533, 2019

3. Kumar R, Chandra A : Terminal myelocystocele. Indian J Pediatr 69 : 1083-1086, 2002

4. Lee JY, Phi JH, Kim SK, Cho BK, Wang KC : Urgent surgery is needed when cyst enlarges in terminal myelocystoceles. Childs Nerv Syst 27 : 2149-2153, 2011

5. McLone DG, Naidich TP : Terminal Myelocystocele. Neurosurgery 16 : 36-43, 1985

6. Morioka T, Hashiguchi K, Yoshida F, Matsumoto K, Miyagi Y, Nagata S, et al. : Neurosurgical management of occult spinal dysraphism associated with OEIS complex. Childs Nerv Syst 24 : 723-729, 2008

7. Pang D, Zovickian J, Lee JY, Moes GS, Wang KC : Terminal myelocystocele: surgical observations and theory of embryogenesis. Neurosurgery 70 : 1383-1405; discussion 1404-1405, 2012

8. Wataya T, Horikawa K, Kitagawa M, Tashiro Y : Thoracic meningocele in lumbo-costo-vertebral syndrome in a child: possible enlargement with repeated motion by anchoring to the diaphragm. J Neurosurg Pediatr 18 : 183-186, 2016 